\title{
Optimal Two Stage Open Shop Specially Structured Scheduling To Minimize the Rental Cost, processing time Associated with Probabilities including transportation time
}

\author{
${ }^{1}$ Deepak Gupta, ${ }^{2}$ Shashi Bala, ${ }^{3}$ Payal Singla \\ ${ }^{1}$ Prof. \& Head, Department of Mathematics M.M.University, Mullana, Ambala,India \\ ${ }^{2}$ Department of Mathematics M. P. College for Women, Mandi Dabwali, India \\ ${ }^{3}$ Department of Mathematics M.M.University, Mullana, Ambala,India
}

\begin{abstract}
The present paper considers a more practical problem of scheduling $n$ jobs in a two machine specially structured open shop to minimize the rental cost. Further the processing time of jobs is associated with their respective probabilities including transportation time. In most of literature the processing times are always considered to be random, but there are significant situations in which processing times are not merely random but bear a well defined structural relationship to one another. The objective of this paper is to minimize the rental cost of machines under a specified rental policy. The algorithm is demonstrated through the numerical illustration.
\end{abstract}

Keywords: Open Shop Scheduling, Rental Policy, Processing Time, Utilization Time, Make span, Idle Time. Mathematical Subject Classification: 90B30, $90 B 35$

\section{Introduction}

In scheduling problems for shop processing system, each job has to be processed on a specific machine. A job passing through the machines following a certain order is known as the processing route. If the processing routes are not given in advance, but have to be chosen, the processing system is called the open shop. If the processing routes are fixed beforehand, and are same for all the jobs, the system is called flow shop. Such an open shop environment arise in many industrial application viz, automobile repairs, quality control centres, semiconductor manufacturing, setellite communication etc. Johnson [16] gave a procedure to obtain the optimal sequence for $\mathrm{n}$-jobs, two - three machines flow shop scheduling problem with an objective to minimize the makespan. . Further the work was developed by Jackson.J.R.[15], Baker, K. R[3]. smith et al [14], Gupta, J.N.D. [12], Maggu \& Dass [18], Gupta Deepak et. al.[10,11], Anup [1] T. Gonzalez, S. Sahni[24], V.A. Strusevich [25,26], Singh T.P.et al [22,23], Yoshida and Hitomi [28] etc. by considering various parameter.

Singh T.P and Gupta Deepak and Rajendra [23] made an attempt to study the optimal two stage open shop scheduling in which processing time is associated with their respective probabilities including job block criteria.

Open shop scheduling differ from flow shop in the sense that there are no restrictions placed on the order of the machines i.e. operations can be performed in any order A to B or B to A and not known in the advance. Gupta and Singh [5] studied the $n * 2$ open shop problem to minimize the total idle time of the machines in which the probabilities associated with processing time including job block criteria In a specially structured flow shop scheduling the data is not merely random but bears a well defined structural relation. Gupta J.N.D. [12] gave an algorithm to find the optimal schedule for specially structured flow shop scheduling. Gupta Deepak, Sharma and Shashi [7] introduce the concept of specially structured flow shop scheduling to minimize the rental cost of machines in which processing times are associated with probabilities. The present paper is an attempt to minimize the rental cost of machines by introducing the concept of transportation time, under specially structured open shop scheduling. The transportation times (loading time, moving time and unloading etc.) from one machine to another are also not negligible and therefore must be included in the job processing. However, in some application, transportation time have major impact on the performance measures considered for the scheduling problem so they need to considered separately hence become significant. Thus the problem in the present paper has wider and practically more applicable and provides suitable results. An algorithm has been developed to minimize the maximum utilization time and hence minimize rental cost. The algorithm is demonstrated through numerical example.

\section{Practical Situation}

Open shop scheduling problems arise in several industrial situations. For example, consider a large aircraft garage with specialized work-centers. An airplane may require repairs on its engine and electrical circuit system. These two tasks may be carried out in any order but it is not possible to do these tasks on the same plane 
Optimal Two Stage Open Shop Specially Structured Scheduling To Minimize the Rental Cost,

simultaneously. Other applications of open shop scheduling problems are in automobile repair, quality control centers, semiconductor manufacturing, teacher-class assignments, examination scheduling, and satellite communications etc. In the era of globalization or global uncertainties, to meet the challenges of the business, one does not always have enough funds to invest in advanced machines to update the technology. Under such circumstances the machines has to be taken on rent. Rental of machines is an affordable and quick solution for having the equipment and up gradation to new technology. . Further, when the machines on which jobs are to be processed are planted at different places, the transportation time which include the loading time, moving time and unloading time etc. has a significant role in production concern and hence significant.

\section{Notations}

$S \quad:$ Sequence of jobs $1,2,3, \ldots, \mathrm{n}$

$S_{k} \quad$ : Sequence obtained by applying Johnson's procedure, $\mathrm{k}=1,2,3,-----\mathrm{r}$.

$M_{j} \quad:$ Machine j=1,2,

$a_{i j} \quad$ : Processing time of $i^{t h}$ job on machine $M_{j}$

$p_{i j} \quad$ : Probability associated to the Processing time $a_{i j}$

$A_{i j} \quad$ : Expected processing time.

$T_{i l \rightarrow 2} \quad$ : Transportation time of $i^{\text {th }}$ job from $1^{\text {st }}$ machine to $2^{\text {nd }}$ machine.

$t_{i j}\left(S_{k}\right) \quad$ : Completion time of $i^{\text {th }}$ job of sequence $S_{k}$ on machine $M_{j}$

$U_{j}\left(S_{k}\right) \quad$ : Utilization time for which machine $M_{j}$ is required

$R\left(S_{k}\right) \quad$ : Total rental cost for the sequence $S_{k}$ of all machine

$C_{i} \quad$ : Renal cost of $i^{\text {th }}$ machine.

$C T\left(S_{k}\right) \quad$ : Total completion time of the jobs for sequence $S_{k}$

\section{Definition}

Completion time of $i^{\text {th }}$ job on machine $M_{j}$ is denoted by $t_{i j}$ and is defined as: $t_{i j}=\max \left(t_{i-1, j}, t_{i, j-1+} T_{i l \rightarrow 2}\right)+a_{i j} \times p_{i j}$ for $j \geq 2$.

$=\max \left(t_{i-1, j}, t_{i, j-1+}+T_{i l \rightarrow 2}\right)+A_{i j}$, where $A_{i j}=$ Expected processing time of $i^{\text {th }}$ job on $j^{\text {th }}$ machine.

\section{Rental Policy(P)}

The machines will be taken on rent as and when they are required and are returned as and when they are no longer required. i.e. the first machine will be taken on rent in the starting of the processing the jobs, $2^{\text {nd }}$ machine will be taken on rent at time when $1^{\text {st }}$ job is completed on the $1^{\text {st }}$ machine.

\section{Problem Formulation}

Let $\mathrm{n}$ jobs $1,2, \ldots \ldots \ldots, \mathrm{n}$ be processed on two machines $M_{1}$ and $M_{2}$ in any order i.e. the jobs will be processed first on $\mathrm{M}_{1}$ and then on $\mathrm{M}_{2}$ or first on $\mathrm{M}_{2}$ and then on $\mathrm{M}_{1}$ under the specified rental policy . Let $a_{i j}$ be the processing time of $i^{\text {th }}$ job $(i=1,2, . ., \mathrm{n})$ on machine $\mathrm{M}_{\mathrm{j}}$ and $\mathrm{p}_{\mathrm{ij}}$ be the probabilities associated with $\mathrm{a}_{\mathrm{ij}} . \mathrm{A}_{i j}$ be the expected processing time of $i^{\text {th }}$ job on machine $\mathrm{M}_{\mathrm{j}}(\mathrm{j}=1,2)$ such that

either $\quad A_{i 1} \geq A_{j 2}$

or $\quad \mathrm{A}_{\mathrm{i} 1} \leq \mathrm{A}_{\mathrm{j} 2}$ for all values of $i, \mathrm{j} . \mathrm{i} \neq \mathrm{j}$

Let $\mathrm{T}_{\mathrm{i}, 1 \rightarrow 2}$ be the transportation time of $\mathrm{i}^{\text {th }}$ job from $1^{\text {st }}$ machine to the $2^{\text {nd }}$ machine which is same as transportation time from $2^{\text {nd }}$ machine to $1^{\text {st }}$ machine i.e. $T_{i, 1 \rightarrow 2}$ is same as $T_{i, 2 \rightarrow 1}$.

Our aim is to find the optimal or near optimal sequence $\left\{S_{k}\right\}$ of the jobs which minimize the rental cost of machines.

The mathematical model of the problem in matrix form can be stated as:

\begin{tabular}{|l|l|l|l|l|l|}
\hline Jobs & \multicolumn{2}{|l|}{ Machine $\mathrm{M}_{1}$} & $\begin{array}{l}\mathrm{T}_{\mathrm{i}, 1 \rightarrow 2} \\
\mathrm{~T}_{\mathrm{i}, 2 \rightarrow 1}\end{array}$ & \multicolumn{2}{l|}{ Machine $\mathrm{M}_{2}$} \\
\hline$i$ & $a_{i 1}$ & $p_{i 1}$ & & $a_{i 2}$ & $p_{i 2}$ \\
\hline 1 & $a_{11}$ & $p_{21}$ & $T_{11 \rightarrow 2}$ & $a_{12}$ & $p_{12}$ \\
\hline 2 & $a_{21}$ & $p_{21}$ & $T_{21 \rightarrow 2}$ & $a_{22}$ & $p_{22}$ \\
\hline 3 & $a_{31}$ & $p_{31}$ & $T_{31 \rightarrow 2}$ & $a_{32}$ & $p_{32}$ \\
\hline- & - & - & - & - & - \\
\hline$n$ & $a_{n 1}$ & $p_{n 1}$ & $T_{n 1 \rightarrow 2}$ & $a_{n 2}$ & $p_{n 2}$ \\
\hline
\end{tabular}

Table : 1

Mathematically, the problem is stated as: Minimize 
$R\left(S_{k}\right)=\sum_{i=1}^{n} A_{i 1} \times C_{1}+U_{2}\left(S_{k}\right) \times C_{2}$

Subject to constraint: Rental Policy(P).

Our objective is to minimize rental cost of machines while minimizing the utilization time.

\section{Assumptions}

1. Two jobs cannot be processed on a single machine at a time.

2. Jobs are independent to each other.

3. Per-emption is not allowed i.e. once a job started on a machine, the process on that machine cannot be stopped unless the job is completed.

4. Either the processing time of the $i^{\text {th }}$ job of machine $M_{1}$ is longer than the expected processing time of $j^{\text {th }}$ job on machine $\mathrm{M}_{2}$ or the processing time $\mathrm{i}^{\text {th }}$ job on machine $\mathrm{M}_{1}$ is shorter than the expected processing time of $\mathrm{j}^{\text {th }}$ job on machine $\mathrm{M}_{2}$ for all $\mathrm{i}, \mathrm{j}$.

$$
\begin{array}{ll}
\text { i.e. either } & A_{i 1} \geq A_{j 2} \\
\text { or } & A_{i 1} \leq A_{j 2}
\end{array} \quad \text { for all i,j. } i \neq j
$$

5. $\sum \mathrm{P}_{\mathrm{i} 1}=1, \sum \mathrm{p}_{\mathrm{i} 2}=1,0 \leq \mathrm{p}_{\mathrm{i} 1} \leq 1,0 \leq \mathrm{p}_{\mathrm{i} 2} \leq 1$.

6. Let $n$ jobs be processed through two machines $M_{1}$ and $M_{2}$ in order $M_{1} M_{2}$ and in order $M_{2} M_{1}$.

7. Machine break down is not considered

8. Transportation time from first machine to second machine and second machine to first machine is same.

9. Transporting device is always available.

\section{Algorithm}

Step 1: Calculate the expected processing times, $A_{i j}=a_{i j} \times p_{i j} \forall i, j$.

Step 2: $\mathrm{A}_{\mathrm{i} 1}^{\prime}=\mathrm{A}_{\mathrm{i} 1+}+\mathrm{t}_{i l \rightarrow 2}, \quad \mathrm{~A}_{\mathrm{i} 2}^{\prime}=\mathrm{A}_{\mathrm{i} 2+} \mathrm{t}_{i l \rightarrow 2}$

Step 3: Check the condition

Either $\quad A_{i 1}^{\prime} \geq A_{i 2}^{\prime}$

or $\quad \mathrm{A}_{\mathrm{i} 1}^{\prime} \leq \mathrm{A}_{\mathrm{i} 2}^{\prime}$ for all $i$ and $\mathrm{j}, \mathrm{i} \neq \mathrm{j}$, if conditions hold good, go to step4,else modify the data to reduce the problem in standard form.

Step 4: Obtain the job $\mathrm{J}_{1}$ (say) having maximum processing time on $1^{\text {st }}$ machine and job $\mathrm{J}_{\mathrm{n}}$ (say) having minimum processing time on $2^{\text {nd }}$ machine.

Step 5: If $J_{1} \neq J_{n}$ then put $J_{1}$ on the first position and $J_{n}$ on the last position \& go to step 8, Otherwise go to step 6.

Step 6: Take the difference of processing time of job $\mathrm{J}_{1}$ on first machine from job $\mathrm{J}_{2}$ (say) having next maximum processing time on first machine. Call this difference as $\mathrm{G}_{1}$. Also, take the difference of processing time of job $\mathrm{J}_{\mathrm{n}}$ on second machine from job $\mathrm{J}_{\mathrm{n}-1}$ (say) having next minimum processing time on second machine. Call the difference as $\mathrm{G}_{2}$.

Step 7: If $G_{1} \leq G_{2}$ put $J_{n}$ on the last position and $J_{2}$ on the first position otherwise put $J_{1}$ on $1^{\text {st }}$ position and $J_{n-1}$ on the last position.

Step 8: Arrange the remaining (n-2) jobs between $1^{\text {st }}$ job \& last job in any order; thereby we get the sequences $\mathrm{S}_{1}, \mathrm{~S}_{2} \ldots \mathrm{S}_{\mathrm{r}}$ (when the order of machines is $\mathrm{M}_{1} \rightarrow \mathrm{M}_{2}$ ) and the sequences $\mathrm{S}_{1}^{\prime}, \mathrm{S}_{2}^{\prime} \ldots \mathrm{S}_{\mathrm{r}}^{\prime}$ (when the order of machines is $\mathrm{M}_{2} \rightarrow \mathrm{M}_{1}$ ).

Step 9: Compute the total completion time $\mathrm{CT}\left(\mathrm{S}_{\mathrm{k}}\right)$ and $\mathrm{CT}\left(\mathrm{S}_{\mathrm{k}}^{\prime}\right)$ by computing in - out table for sequences $\mathrm{S}_{\mathrm{k}}$ and $\mathrm{S}_{\mathrm{k}}^{\prime}(\mathrm{k}=1,2, \ldots . \mathrm{r}$.$) .$

Step 10: Calculate utilization time $\mathrm{U}_{2}\left(\mathrm{~S}_{\mathrm{k}}\right)$ and $\mathrm{U}_{2}\left(\mathrm{~S}_{\mathrm{k}}^{\prime}\right)$ of $2^{\text {nd }}$ machine as follows:

$$
\begin{aligned}
& \mathrm{U}_{2}\left(\mathrm{~S}_{\mathrm{k}}\right)=\mathrm{CT}\left(\mathrm{S}_{\mathrm{k}}\right)-\mathrm{A}_{11}\left(\mathrm{~S}_{\mathrm{k}}\right) ; k=1,2, \ldots \mathrm{r} . \\
& \mathrm{U}_{2}\left(\mathrm{~S}_{\mathrm{k}}^{\prime}\right)=\mathrm{CT}\left(\mathrm{S}_{\mathrm{k}}\right)-\mathrm{A}_{12}\left(\mathrm{~S}_{\mathrm{k}}^{\prime}\right) ; k=1,2, \ldots \mathrm{r} .
\end{aligned}
$$

Step 11: Find rental cost

$$
R\left(S_{1}\right)=\sum_{i=1}^{n} A_{i 1}\left(S_{1}\right) \times C_{1}+U_{2}\left(S_{1}\right) \times C_{2}
$$

where $C_{1} \& C_{2}$ are the rental cost per unit time of machine $M_{1} \& M_{2}$ respectively.

Step 12: Find rental cost

$R\left(S_{1}^{\prime}\right)=\sum_{i=1}^{n} A_{i 2}\left(S_{1}^{\prime}\right) \times C_{2}+U_{2}^{\prime}\left(S_{1}^{\prime}\right) \times C_{1}$

where $C_{1} \& C_{2}$ are the rental cost per unit time of machine $M_{1} \& M_{2}$ respectively. 
Optimal Two Stage Open Shop Specially Structured Scheduling To Minimize the Rental Cost, Step 13: Find $R(S)=\min \left\{R\left(S_{1}\right), R\left(S_{1}^{\prime}\right)\right\}$.

\section{Numerical Illustration}

Consider 6 jobs, 2 machines problem to minimize the rental cost, processing time associated with their respectively probabilities and transportation time $\mathrm{T}_{\mathrm{i}, 1 \rightarrow 2}$ or $\mathrm{T}_{\mathrm{i}, 2 \rightarrow 1}$ given in the following table.

The rental cost per unit time for machines $\mathrm{M}_{1}$ and $\mathrm{M}_{2}$ are 10 and 5 units respectively. Our objective is to obtain optimal schedule and order of machines to minimize the total production time subject to minimization of the rental cost of the machines, under the rental policy $P$.

\begin{tabular}{|l|l|l|l|l|l|}
\hline $\begin{array}{l}\text { Jobs } \\
i\end{array}$ & \multicolumn{2}{|c|}{ Machine $\mathrm{M}_{1}$} & $\mathrm{~T}_{\mathrm{i}, 1 \rightarrow 2}$ & \multicolumn{2}{c|}{ Machine $\mathrm{M}_{2}$} \\
& $a_{i 1}$ & \multicolumn{1}{|c|}{$p_{i 1}$} & & $a_{i 2}$ & $p_{i 2}$ \\
\hline 1 & 40 & 0.2 & 3 & 75 & 0.2 \\
\hline 2 & 30 & 0.3 & 3 & 80 & 0.2 \\
\hline 3 & 45 & 0.1 & 6 & 85 & 0.2 \\
\hline 4 & 35 & 0.2 & 2 & 90 & 0.2 \\
\hline 5 & 25 & 0.1 & 4 & 95 & 0.1 \\
\hline 6 & 50 & 0.1 & 3 & 100 & 0.1 \\
\hline
\end{tabular}

Table: 2

Solution: As per step 1: the expected processing time for machines $M_{1}$ and $M_{2}$ is as follow:

\begin{tabular}{|l|l|l|l|}
\hline Jobs & \multicolumn{1}{|c|}{ Machine $\mathrm{M}_{1}$} & Machine $\mathrm{M}_{2}$ & $\begin{array}{c}\mathrm{T}_{\mathrm{i}, 1 \rightarrow 2} \\
\mathrm{~T}_{\mathrm{i}, 2 \rightarrow 1}\end{array}$ \\
\hline 1 & $\mathrm{~A}_{\mathrm{i} 1}$ & $\mathrm{~A}_{\mathrm{i} 2}$ & \\
\hline 2 & 8.0 & 15.0 & 3 \\
\hline 3 & 9.0 & 16.0 & 3 \\
\hline 4 & 4.5 & 17.0 & 6 \\
\hline 5 & 7.0 & 18.0 & 2 \\
\hline 6 & 2.5 & 9.5 & 4 \\
\hline
\end{tabular}

Table: 3

As per step 2:the expected processing time with transportation time for machine $\mathrm{M}_{1}$ and for machine $\mathrm{M}_{2}$ is as follow:

\begin{tabular}{|l|l|l|}
\hline \multicolumn{1}{|c|}{ Jobs } & \multicolumn{1}{c|}{$\begin{array}{c}\text { Machine } \mathrm{M}_{1} \\
\tilde{\mathrm{A}}_{\mathrm{i} 1}^{\prime}\end{array}$} & $\begin{array}{c}\text { Machine } \mathrm{M}_{2} \\
\mathrm{~A}_{\mathrm{i} 2}\end{array}$ \\
\hline 1 & 11.0 & 18.0 \\
\hline 2 & 12.0 & 19.0 \\
\hline 3 & 10.5 & 23.0 \\
\hline 4 & 9.0 & 20.0 \\
\hline 5 & 6.5 & 13.5 \\
\hline 6 & 8.0 & 13.0 \\
\hline
\end{tabular}

Table: 4

As per step 3: For order $M_{1} \square \mathbf{M}_{2}$

$\mathrm{A}_{\mathrm{i} 1}^{\prime} \leq \mathrm{A}_{\mathrm{i} 2}^{\prime}$ for all $i$ and $\mathrm{j}, \mathrm{i} \neq \mathrm{j}$ i.e. data is in standard form.

Also $\max \mathrm{A}^{\prime}{ }^{\prime}=12$ which is for job 2 i.e. $\mathrm{J}_{1}=2$.

And $\min A_{i 2}^{\prime}=13.0$ which is for job 6 i.e. $J_{n}=6$.

Since $\mathrm{J}_{1} \neq \mathrm{J}_{\mathrm{n}}$ As per step 6 , job 2 will be on $1^{\text {st }}$ position and job 6 will be on the last position.

Therefore as per step 9 , all 24 possible optimal sequences are:

$\mathrm{S}_{1}: \quad 2-5-1-3-4-6$

$S_{2}: 2-5-1-3-4-6$

$S_{24}: 2-4-1-3-5-6$

The total elapsed time is same for all these 24 possible sequences

$\mathrm{S}_{1}, \mathrm{~S}_{2}, \mathrm{~S}_{3} \ldots, \mathrm{S}_{24}$.

The in- -out table for any of these sequences $S_{1}, S_{2} \ldots . S_{24}$

Say for $\mathrm{S}_{1}: 2-5-1-3-4-6$ is as follow: 


\begin{tabular}{|l|l|l|}
\hline Jobs $i$ & $\begin{array}{l}\text { Machine } \mathrm{M}_{1} \\
\text { In }- \text { out }\end{array}$ & $\begin{array}{l}\text { Machine } \mathrm{M}_{2} \\
\text { In - out }\end{array}$ \\
\hline 2 & $0-9.0$ & $12.0-25.0$ \\
\hline 5 & $9.0-11.5$ & $25.0-34.5$ \\
\hline 1 & $11.5-19.5$ & $34.5-49.5$ \\
\hline 3 & $19.5-24.0$ & $49.5-66.5$ \\
\hline 4 & $24.0-31.0$ & $66.5-84.5$ \\
\hline 6 & $31.0-36.0$ & $84.5-94.5$ \\
\hline
\end{tabular}

Table: 5

Therefore the total elapsed time $=\mathrm{CT}\left(\mathrm{S}_{1}\right)=94.5$ units

And utilization time for $\mathrm{M}_{2}=\mathrm{U}_{2}\left(\mathrm{~S}_{1}\right)=82.5$ units

Also

$\sum_{i=1}^{n} A_{i 2}=36.0$

There rental cost $\mathrm{R}\left(\mathrm{S}_{1}\right) \quad=36.0 \times 10+82.5 \times 5$

$$
=360+412.5
$$

$=772.5$ unit

As per step 3: For order $\mathrm{M}_{2} \rightarrow \mathrm{M}_{1}$

$\mathrm{A}_{\mathrm{i} 1}^{\prime} \leq \mathrm{A}_{\mathrm{j} 2}^{\prime}$ for all $i$ and $\mathrm{j}, \mathrm{i} \neq \mathrm{j}$ i.e. data is in standard form

As per step 4: $\max A_{i 2}^{\prime}=23.0$ which is for job 3 i.e. $\mathrm{J}_{1}=3$

And min $A_{i 1}^{\prime}=6.5$ which is for job 5 i.e. $\mathrm{J}_{\mathrm{n}}=5$

Since $\mathrm{J}_{1} \neq \mathrm{J}_{\mathrm{n}}$ As per step 6 job 3 will be on $1^{\text {st }}$ position and job 5 will be on the last position.

As per step 9 all 24 possible optimal sequences are

$S_{1}^{\prime}: 3-1-6-2-4-5$

$S_{2}^{\prime}: 3-1-6-2-4-5$

$\mathrm{S}_{24}: 3-4-6-2-1-5$

The total elapsed time is same for all 24 sequences $S_{1}^{\prime}, S_{2}^{\prime} \ldots \ldots . ., S_{24}$.

The in - out table for any of these 24 sequences $S_{1}^{\prime}, S_{2}^{\prime}, \ldots . . S_{24}$

Say for $S_{1}^{\prime}: 3-1-6-2-4-5$

\begin{tabular}{|l|l|l|}
\hline Jobs $i$ & $\begin{array}{l}\text { Machine } \mathrm{M}_{2} \\
\mathrm{In}-\text { out }\end{array}$ & $\begin{array}{l}\text { Machine } \mathrm{M}_{1} \\
\mathrm{In}-\text { out }\end{array}$ \\
\hline 3 & $0-17$ & $23-27.5$ \\
\hline 1 & $17-32$ & $35-43.0$ \\
\hline 6 & $32-42$ & $45-50$ \\
\hline 2 & $42-58$ & $61-70$ \\
\hline 4 & $58-76$ & $78-85.0$ \\
\hline 5 & $76-85.5$ & $89.4-91.9$ \\
\hline
\end{tabular}

Table: 6

Therefore the total elapsed time $=\mathrm{CT}\left(S_{1}^{\prime}\right)=91.9$ units

And utilization time for $\mathrm{M}_{1}=\mathrm{U}_{2}\left(S_{1}^{\prime}\right)=91.9-23$

$$
=68.9 \text { units }
$$

$\sum_{i=1}^{\substack{\text { Also } \\ n}} A_{i 2}=85.5$

$$
\begin{aligned}
\text { Therefore rental cost } \mathrm{R}\left(S_{1}^{\prime}\right) & =85.5 \times 5+68.9 \times 10 \\
& =427.5+689 \\
& =1116.5 \text { units }
\end{aligned}
$$


Optimal Two Stage Open Shop Specially Structured Scheduling To Minimize the Rental Cost,

$\mathrm{R}(\mathrm{S})=\min \left\{\mathrm{R}\left(\mathrm{S}_{1}\right), \mathrm{R}\left(S_{1}^{\prime}\right)\right\}=\min \{772.5,1116.5\}$

$=772.5=\mathrm{R}\left(\mathrm{S}_{1}\right)$

We conclude that optimal schedule: $S_{1}=2-5-1-3-4-6$, which is for order $M_{1}$ to $M_{2}$ gives minimum rental cost.

\section{Remarks}

If we find optimal schedule by Johnson [16], we get the optimal schedule as $\mathrm{S}_{11}=5-6-4-3-1-$ 2 , for order $M_{1} \rightarrow M_{2}$. And optimal schedule as $S_{21}=2-1-3-4-6-5$, for order $M_{2} \rightarrow M_{1} . R(S)=\min \left\{R\left(S_{11}\right)\right.$, $\left.\mathrm{R}\left(\mathrm{S}_{21}\right)\right\}=\min \{787.5,1157.5\}$

$=787.5=R\left(S_{11}\right)$. Thus rental cost is minimum for schedule $S_{11}=5-6-4-3-1-2$,for order $M_{1} \rightarrow M_{2}$.

\section{Conclusion}

We conclude that the algorithm proposed here is more effective and gives better result as compared to traditional algorithm given by johnson(1954).

The study in $\mathrm{n} \times 2$ open shop specially structured may be further extended by considering various parameters such as weightage of jobs, job block, break in interval etc. problem

The study may further be extended to three stage, $\mathrm{n}$ machine open shop specially structured scheduling

\section{References}

[1] Anup (2002), "On two machine flow shop problem in which processing time assumes probabilities and there exists equivalent for an ordered job block", JISSOR, Vol. XXIII No. 1-4, pp. 41-44.

[2] Bagga P C (1969), "Sequencing in a rental situation”, Journal of Canadian Operation Research Society, Vol.7, pp.152-153.

[3] Baker, K. R. (1974), "Introduction of sequencing and scheduling," John Wiley and Sons, New York.

[4] Bellman, R. (1956), "Mathematical aspects of scheduling theory", J. Soc. Indust. Appl. Math. 4(3),168-205.

[5] Belwal \& Mittal (2008), "n jobs machine flow shop scheduling problem with break down of machines, transportation time and equivalent job block", Bulletin of Pure \& Applied Sciences-Mathematics, Jan - June,2008, source Vol. 27, Source Issue 1.

[6] Chander S, K Rajendra \& Deepak C (1992), "An Efficient Heuristic Approach to the scheduling of jobs in a flow shop", European Journal of Operation Research, Vol. 61, pp.318-325.

[7] Chandramouli, A. B. (2005), "Heuristic approach for $\mathrm{n}$-jobs, 3-machines flow-shop scheduling problem involving transportation time, breakdown time and weights of jobs", Mathematical and ComputationalApplications 10(2), pp 301-305.

[8] Chandrasekharan R (1992), "Two-Stage Flowshop Scheduling Problem with Bicriteria " O.R. Soc. ,Vol. 43, No. 9, pp.871-84.

[9] D. Rebaine, V.A. Strusevich(1998), Two-machine open shop scheduling with special transportation times, CASSM R\&D Paper 15, University of Greenwich, London, UK.

[10] Gupta Deepak (2005), "Minimizing rental cost in two stage flow shop, the processing time associated with probabilities including job block", Reflections de ERA, Vol 1, No.2, pp.107-120.

[11] Gupta Deepak, Sharma Sameer and Shashi Bala (2012), "Specially Structured Two Stage Flow Shop Scheduling To Minimize the Rental Cost", International Journal of Emerging trends in Engineering and Development, Vol. 1, Issue 2, pp.206-215.

[12] Gupta J N D (1975), “Optimal Schedule for specially structured flow shop”, Naval Research Logistic, Vol.22, No.2, pp. 255-269.

[13] Gupta J N D (1988), “Two stage hybrid flow shop scheduling problem”, J. Ope. Res. Soc., Vol. 39, No. 4, pp. 359 - 364.

[14] Ignall E and Schrage L (1965), "Application of the branch and bound technique to some flow shop scheduling problems", Operation Research, Vol.13, pp.400-412.

[15] Jackson, J. R. (1956), “An extension of Johnson's results on job scheduling”, Nav. Res. Log. Quar., 3, pp 201-203.

[16] Johnson S M (1954), "Optimal two and three stage production schedule with set up times included", Naval Research Logistic, Vol.1, No.1, pp. 61-64.

[17] M. Dell'Amico, Shop problems with two machines and time lags, Oper. Res. 44 (1996) 777-787.

[18] Maggu P L and Das G (1977), "Equivalent jobs for job block in job scheduling”, Opsearch, Vol. 14, No.4, pp. $277-281$.

[19] Maggu P.I. and harbans lal (1989) on "job block open shop scheduling problem" PAMS Vol XXIX-pp- $45-51$.

[20] Narian L Bagga P C (2005), "Two machine flow shop problem with availability constraint on each machine", JISSOR, Vol. XXIV $1-4$, pp. 17-24

[21] Pandian \& Rajendran (2010), "Solving Constraint flow shop scheduling problems with three machines", Int. J. Contemp. Math. Sciences, Vol.5, No. 19, pp.921-929.

[22] Singh T P (1985), “On $\mathrm{n} \times 2$ shop problem involving job block. Transportation times and Break-down Machine times”, PAMS, Vol. XXI , pp.1-2.

[23] Singh T P, K Rajindra \& Gupta Deepak (2005), "Optimal three stage production schedule the processing time and set times associated with probabilities including job block criteria”, Proceedings of National Conference FACM-2005,pp. 463-492.

[24] T. Gonzalez, S. Sahni, Open shop scheduling to minimize ÿnish time, J. Assoc. Comput. Mach. 23(1976) 665-679.

[25] V.A. Strusevich (1997), L.A. Hall, An open-shop scheduling problem with a non-bottleneck machine, Oper. Res. Lett. 21 (1997) $11-18$.

[26] V.A. Strusevich, Two-machine open-shop scheduling problem with setup, processing and removal times separated, Comput. Oper. Res. 20 (1993) 597-611.

[27] V.J. Rayward-Smith, D. Rebaine, Open-shop scheduling with delays, Theoret. Inform. Appl. (1992)439 - 448.

[28] Yoshida and Hitomi (1979), "Optimal two stage production scheduling with set up times separated", AIIE Transactions, Vol.11, No. 3,pp. 261-269. 